\title{
MICROSTRUCTURAL STUDY ON THE EFFECTIVENESS OF COMMERCIAL POLYMER EMULSION AS CEMENT ADDITIVES TO MITIGATE EFFLORESCENCE
}

\author{
N. MOHAMED SUTAN ${ }^{1}$, I. YAKUB ${ }^{1}$, S. HAMDAN ${ }^{1} \&$ Z. A. TALIB 2 \\ ${ }^{1}$ Department of Civil Engineering, Chemical Engineering and Energy Sustainability, Mechanical Engineering, \\ Faculty of Engineering, Universiti Malaysia Sarawak, Sarawak, Malaysia. \\ ${ }^{2}$ Department of Physics, Faculty of Science, Universiti Putra Malaysia, Selangor, Malaysia.
}

\begin{abstract}
The occurrence of calcium carbonate $\left(\mathrm{CaCO}_{3}\right)$ efflorescence phenomenon is not new and is generally found in the form of unsightly white deposits on the surface of cement products. It appears just after completion of building construction and causes aesthetically unpleasant sight. This paper presents and discusses the results of microstructural study on the effectiveness of commercial polymer emulsion as cement additives to mitigate efflorescence on cement-based products that are dry-cured in the concrete laboratory at daily room temperature $(\mathrm{T})$ and relative humidity in the range of $18^{\circ} \mathrm{C}-28^{\circ} \mathrm{C}$ and $65 \%-90 \%$, respectively. Polymers used as cement additives were styrene acrylic ester (SAE) and styrene butadiene rubber (SBR) emulsion. Due to their pore-blocking characteristics and interaction with cement to improve mortar quality, they are added into cement to form mortar used for repair purposes. In order to investigate on how they can microstructurally influence efflorescence formation, efflorescence intensities (EI) in terms of percentages of $\mathrm{CaCO}_{3}$ resulting from the combination of puddle test and standard chemical method were compared systematically between all samples on 28, 60 and 90 days and the findings were discussed and corroborated physicochemically using initial surface absorption test, X-ray diffraction (XRD), thermogravimetric analysis (TGA) and morphology using scanning electron microscopy (SEM). Results indicated that $10 \%$ and 5\% SAE addition significantly reduced primary efflorescence and secondary efflorescence, respectively, in comparison to SBR and Control. The influence were on chemical reactivity, interaction between polymer and cement and on the movement of the polymer particles within the hydrating mortar as hydration progressed to form pore-blocking effects in the microstructures of cement-based materials and were reflected in the XRD patterns, TGA/DTG analysis, SEM images and the decreased initial surface water absorption.
\end{abstract}

Keywords: Efflorescence, polymer, XRD, TGA/DTG, SEM, ISAT.

\section{INTRODUCTION}

Modern concrete can be made into a variety of finishes and colours offering architects and the construction industry a material that is both practical and aesthetically pleasing [1]. The currently available inorganic colour pigments, for example iron oxide pigments, are lightfast (colour unaffected if exposed to light) and weather stable. Therefore, the strong colour they impart to concrete could last for decades [2]. Unfortunately, colour changes of concrete can arise due to a well-known yet not well-understood phenomenon called efflorescence [3-6]. White efflorescence salts, while not necessarily increased by concrete pigmentation, are more visually apparent when concrete is coloured than when used in its natural grey form. In addition, coloured concrete tends to be finished to a higher standard for aesthetic purposes. Therefore, efflorescence is particularly noticeable in these circumstances. Efflorescence, which used to be ignored due to its negligible structural effect, is now viewed as a major problem in coloured concrete products $[3,7]$. It could also be an issue of the effectiveness of the adhesion of the protective coating of façade [8]. To date, there are no economical and effective methods to guarantee the prevention of efflorescence [9-11]. ACI 116R-90 defines efflorescence as a deposit of salts, usually white, formed on a surface of concrete or masonry, 
the substance having emerged in solution and subsequently been precipitated by evaporation. There are different generic types of efflorescence that can be identified chemically by the different types of salts, visually by the type of material on which they occurred and sensually by their textures $[12,13]$.

Even though efflorescence is classified as non-degradation durability which is aesthetically unpleasant, some of the worst cases of efflorescence do affect the durability of concrete and reduce the strength due to deterioration. The most significant factors that contribute to efflorescence are the permeation characteristic of the surface near the concrete [10, 14] because in such cases concrete is used for aesthetic functions. Surface appearance of concrete has been as important as its strength. Figure 1(a) shows the efflorescence formation on concrete structure in a building in Malaysia after a few months of completion. This exasperating view can disturb the motive of this decorative architectural concrete structure. Another efflorescence formation shown in Fig. 1(b) is at the staircase of the building. It was observed that the efflorescence at concrete surface also contributes to spalling of concrete surface.

Efflorescence may be primary or secondary as schematically shown in Fig. 2. It is a deposit of crystallized calcium carbonate $\left(\mathrm{CaCO}_{3}\right)$ or calcite on the exposed concrete and cementitious materials manifesting from hazy white layers to thick white crusts [10]. This manifestation is caused primarily by the leaching out of calcium hydroxide $(\mathrm{CH})$ with mineral called Portlandite, one of the hydration products of Portland cement, which is slightly soluble in water, migrating to the concrete surface through the capillary system of the concrete and evaporated to leave the solid $\mathrm{CH}$, which then reacts with atmospheric carbon dioxide $\left(\mathrm{CO}_{2}\right)$ to form $\mathrm{CaCO}_{3}[3-6,11]$. $\mathrm{CH}$ crystals represent $20 \%$ to $25 \%$ of volume of solids in hydrated ordinary Portland cement (OPC) paste $[15,16]$.

Besides the aesthetic problems mentioned, efflorescence is indirectly related to the durability problem in the way that it indicates that substantial $\mathrm{CH}$ leaching is occurring within the concrete and can cause an increase in porosity, increase in permeability and decrease in strength, thereby increasing its vulnerability to aggressive chemicals ingress $[4,5]$. To date, there is no effective method to guarantee the prevention of efflorescence [11, 17]. There are few studies on efflorescence mitigation using different methods and materials discussed by previous researchers such as the use of pozzolanic materials and organic materials [3-7, 10, 11, 17]. Pozzolan such as silica fumes can potentially mitigate efflorescence by pozzolanic reaction that consumes $\mathrm{CH}$ to form additional C-S-H [18]. Meanwhile, organic materials such as

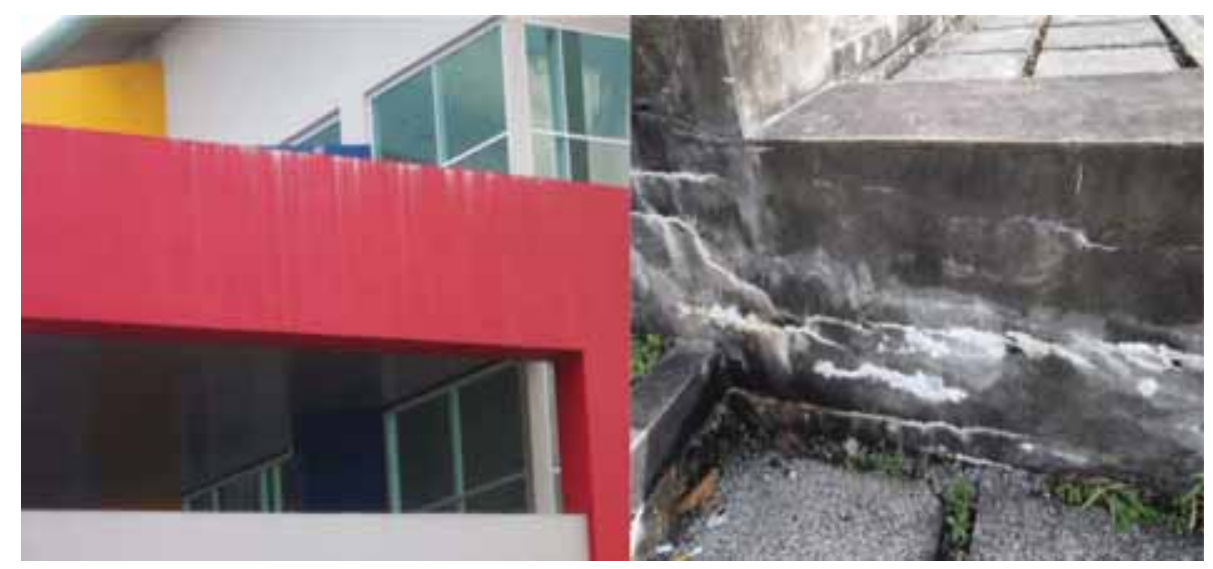

(a)

(b)

Figure 1: Efflorescence formation on concrete structures. 


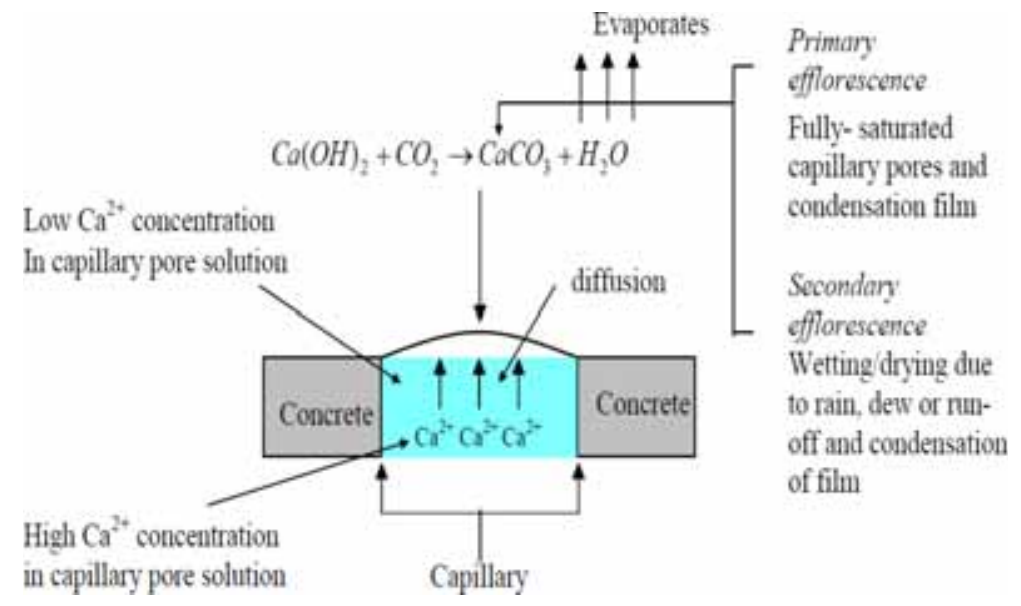

Figure 2: Schematic diagram of Efflorescence from a cross-sectional view of concrete block.

sodium oleate and calcium stearate may react with $\mathrm{CaCO}_{3}$ and minimize efflorescence $[19,20]$. However, there is limited information available on the study of the microstructural interaction of polymer as cement additives. Hypothetically, efflorescence can be mitigated by the minimization of $\mathrm{CH}$ leaching if mortar can be made almost impermeable by blocking the pores using polymer additives where their usage in construction industry is tremendously increasing in the recent years $[21,22]$. Concrete polymer composites are made by replacing a part or all of the cement of the conventional mortar or concrete with the polymers. The concrete polymer composites are generally classified into the following three types by the principles of their process technology such as polymer-modified mortar (PMM) and polymer-modified concrete, polymer mortar and polymer concrete and polymer-impregnated mortar and polymer-impregnated concrete [21-23]. The introduction of 'sticky' plastic spheres makes the cement paste more adhesive and cohesive and thus increases the adhesion. Flexural strength increased because the relatively soft but strong plastic films give greater degree of elasticity. A polymer-rich surface has a plastic coating which is better at resisting the abrasion compare to the unmodified cement paste [21-23]. The polymer spheres are small and can therefore block pores and capillaries and subsequently prevent water loss by reducing shrinkage. The plastic coating on the surface has a much greater resistance to a variety of chemical attacks compared to the unmodified cement paste. A similar mechanism to shrinkage cases, capillary pores are blocked and thus reduce permeability that might mitigate the efflorescence phenomenon [21-23]. Therefore, the purpose of this study is to investigate the effect of polymer additive on efflorescence by focusing on the characterization and morphology of PMM in comparison to conventional mortar.

\section{MATERIALS AND METHODS}

\subsection{Materials preparation}

OPC used in this study, supplied by Cahaya Mata Sarawak Cement Sdn. Bhd (CMS), satisfied Malaysian Standard MS 52: Part 1: 1989 specifications and was recognized by ASTM C150 under ASTM Type 1. The chemical and mineralogical characteristics of the OPC are given in Table 1. Polymers additives used in this study were styrene acrylic ester (SAE) and 
Table 1: Chemical composition of OPC.

\begin{tabular}{lllll}
\hline Compounds & $\mathrm{CaO}$ & $\mathrm{SiO}_{2}$ & $\mathrm{Al}_{2} \mathrm{O}_{3}$ & $\mathrm{Fe}_{2} \mathrm{O}_{3}$ \\
Composition (\%) & 63.0 & 21.79 & 5.75 & 3.25 \\
\hline
\end{tabular}

styrene butadiene rubber (SBR) emulsion of Grade 477 and Grade 29Y46 respectively, from Synthomer, UK. Cement mortar mixtures were prepared using fixed water-to-cement ratio of 0.5 and were casted into a Universal Container $30-\mathrm{ml}(28 \mathrm{~mm}$ diameter $\times 85 \mathrm{~mm}$ height $)$ and $150-\mathrm{mm}$ cube mould. Then, SAE and SBR were added in the proportion of (cement:sand:water) $1: 1.67: 0.5$ by $5 \%, 7 \%$ and $10 \%(\mathrm{w} / \mathrm{w})$ to give two series of SAE- and SBR-added mortar. All the samples were dry-cured in the concrete laboratory at daily room temperature $(\mathrm{T})$ and relative humidity in the range of $18^{\circ} \mathrm{C}-28^{\circ} \mathrm{C}$ and $65 \%-90 \%$, respectively. Samples in Universal Container were used in puddle test (PT), standard chemical method (SCM), X-ray diffraction (XRD), thermogravimetric analysis/derivative thermogravimetric analysis (DTG) (TGA/DTG) and scanning electron microscopy (SEM) while samples in the cube were used in initial surface absorption test (ISAT).

\subsection{Experimental and analysis methods}

\subsubsection{Efflorescence tests}

Efflorescence intensities can be measured using a combination of the two methods namely PT and SCM. First, PT was carried out by applying a constant amount of puddle of water on the surface of concrete. After $24 \mathrm{~h}$ of sample casting, $10 \mathrm{ml}$ of distilled water was added for all samples. After a period of time, visible white deposits were observed on the surface of mortar sample as shown in Fig. 3. The addition of water mimics the contact with water vapour available in air while accelerating efflorescence process, if there is any [7, 10-12].

SCM was then performed to quantify the $\mathrm{CaCO}_{3}$ contained in $1 \mathrm{~g}$ of the sample collected on the surfaces of samples subjected to PT. This was done by determining the amount of weight lost during dissolution of the sample in hydrochloric acid solution $(\mathrm{HCl})$ which was found by subtracting initial sample weight to the weight of samples retained on a filter paper that had been oven-dried at $100^{\circ} \mathrm{C}$ for a day $[18,24]$.

\subsubsection{Characterization of calcium hydroxide $(\mathrm{CH})$ and calcium silicate hydrate $(\mathrm{C}-\mathrm{S}-\mathrm{H})$} using XRD, TGA/DTG and SEM

At specific days, samples were immersed in acetone solution to stop hydration before being used for XRD (28, 60 and 90), TGA/DTG (28) and SEM (28) analysis. Fine powder samples that passed a $75-\mu \mathrm{m}$ sieve were prepared from the samples to be analysed using XRD and TGA/DTG. In the XRD analysis, PANalytical equipment was used using $\mathrm{CuK} \alpha$ radiation of wavelength $0.1546 \mathrm{~nm}$, whereas for TGA/DTG analysis, TA Analyzer was used under $100 \mathrm{ml} / \mathrm{min}$ nitrogen flow in $200^{\circ} \mathrm{C}-1000^{\circ} \mathrm{C}$ temperature range with $10^{\circ} \mathrm{C} / \mathrm{min}$ of elevation. Furthermore, polished samples were also prepared for analysis using SEM (JSM-6701F) according to ASTM C 1723-10 (2010) code of practice.

\subsubsection{Initial surface absorption test}

The initial rate of water absorbed at mortar surface was measured using ISAT according to BS 1881: Part 5 and Part 208. The general arrangement of the test apparatus is shown in Fig. 4. All apparatus were washed in a soap solution to minimize the surface tension. Though 


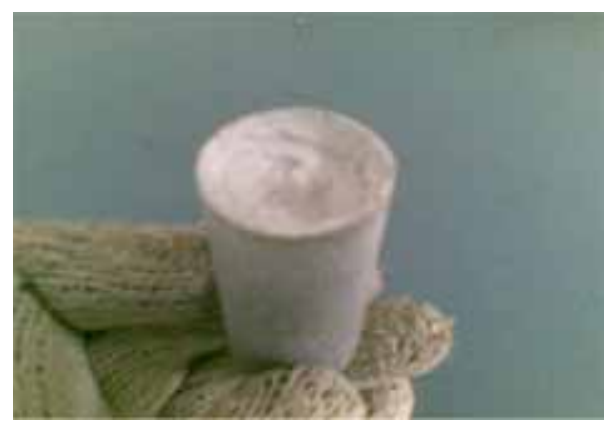

Figure 3: Efflorescence (white colour) is observed on the mortar samples.
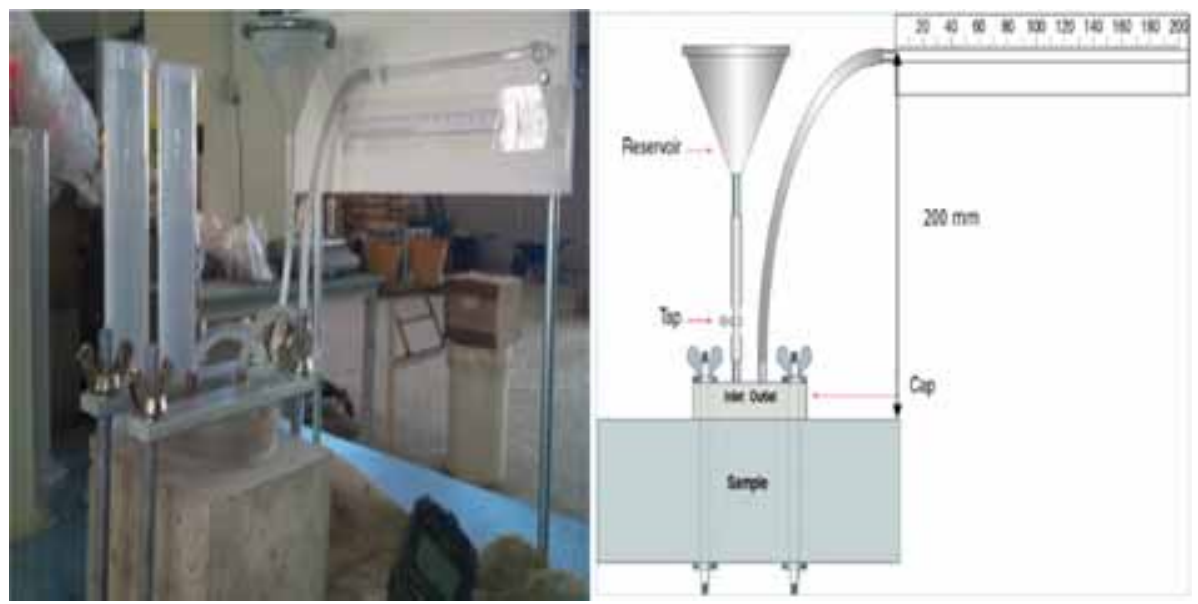

Figure 4: Setting of ISAT according to BS 1881: Part 5 and Part 208.

normally ISAT requires samples to be dried for 7 to 14 days prior to test, laboratory condition and existing moisture level restrict the water absorption which requires the specimens to be oven-dried for only $24 \mathrm{~h}$. Then the samples were cooled for 1 day to prevent water suction due to heat.

A known specimen surface area was contacted with distilled water using a plastic cap of 85-mm diameter connected to a reservoir via a tube. Water level in the cap can be observed because of the material used as the cap is clear acrylic and this made possible the complete renewal of air. Besides, the cap was clamped to the specimen using gasket for even pressure and silicon sealant was used to tighten the seal around the perimeter.

As the reservoir was connected to the inlet of the cap, a capillary tube of $1.7 \mathrm{~mm}$ diameter was attached to the outlet of the cap. At the end of the tube, that is at least $200 \mathrm{~mm}$ above the mortar surface was a horizontal bore glass tube of $1.9 \mathrm{~mm}$ diameter and $180 \mathrm{~mm}$ length. This height is enough to create pressure for water absorption on the surface. The connection to reservoir was cut soon after the cap was filled completely with water. After that, the volumetric flow rate was obtained from the change in distance of flow along the glass tube which is scaled and calibrated to represent $0.01 \mathrm{ml} / \mathrm{m}^{2} / \mathrm{s}$. The readings were 
taken for every $10 \mathrm{~s}$ in 1 -h period of time. The average absorption rate can be determined as in equation (1);

$$
f=\frac{T}{t} \times D \times 0.01 \frac{m l}{m^{2} . s}
$$

where,

$f=$ flow in $\mathrm{ml} / \mathrm{m}^{2} / \mathrm{s}$

$T=$ total test time in seconds,

$t=$ test point time period in seconds,

$D=$ no. of scale divisions during period $t$.

\section{RESULTS AND DISUSSIONS}

\subsection{Efflorescence tests}

Figure 5 shows the percentage of $\mathrm{CaCO}_{3}$ collected from the surfaces of SAE- and SBRmodified mortar samples of $0.5 \mathrm{w} / \mathrm{c}$ ratio for day 28,60 and 90 , respectively. The figure clearly shows that $10 \% \mathrm{SAE}$ addition exhibited the least $\mathrm{CaCO}_{3}$ formation in comparison to SBR and Control samples. This is in agreement with previous findings that established the $10 \%$ optimum addition of SAE on early age of hydration [21-23]. On the other hand, 5\% SAE addition manifested the lowest secondary efflorescence. SAE contains ester which favours $\mathrm{Ca}^{2+}$ available in the mortar boundary [25]. This affinity causes crosslink between ester molecules and the cation from $\mathrm{CH}$ which binds the molecules to the copolymer. Eventually, $\mathrm{CH}$ leach from mortar boundary that induces efflorescence can be prevented. On the contrary, SBR does not react chemically with cement hydration products, but it blocks $\mathrm{CH}$ leaching physically. Initially, only hydrophobic sites of the rubber occupy the pores and capillary that contains no water. When water in mortar boundary is removed as the mortar is

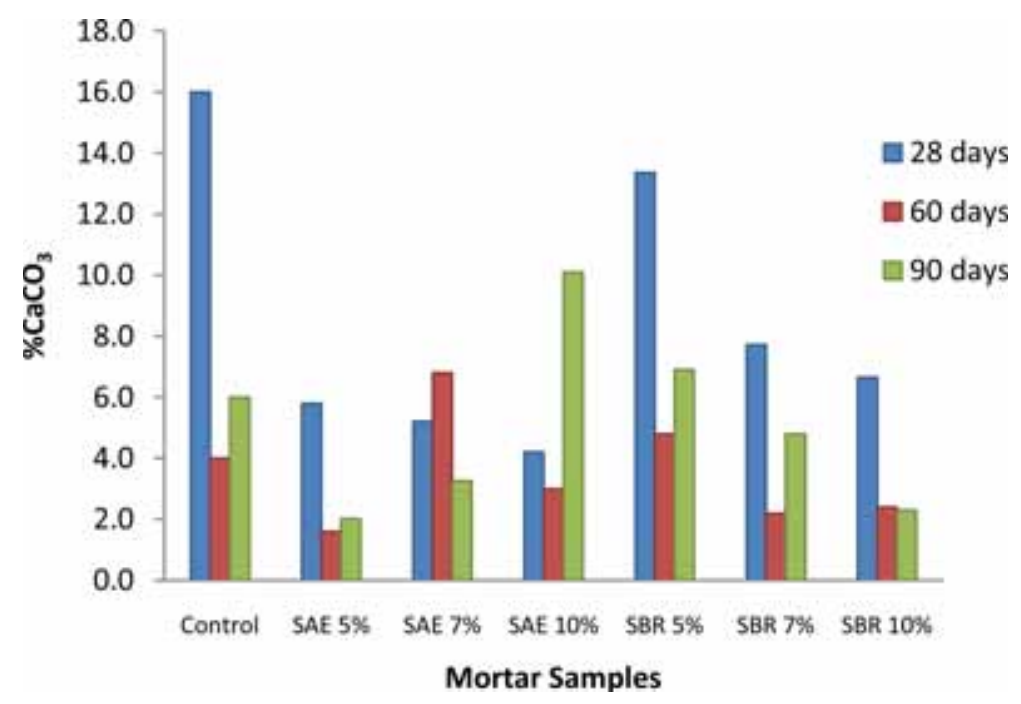

Figure 5: Comparison of percentage (\%) of $\mathrm{CaCO}_{3}$ for all samples for 28, 60 and 90 days. 
aging, hydrophilic sites joined the hydrophobic parts to coalesce and form a film that cover the pores [21-23]. Consequently, $\mathrm{CH}$ has limited path to leach-out to the surface of mortar which prevented the production of efflorescence. However, this process requires drying, which could take at least 28 days of mortar age so it is slower compared to the reaction between $\mathrm{SAE}$ and $\mathrm{CH}$. Figure 5 also shows the $\%$ of $\mathrm{CaCO}_{3}$ decreases, between 60 and 90 days of aging for Control sample while the $\%$ of $\mathrm{CaCO}_{3}$ increases for all the other samples containing SAE and SBR. This was mainly due to the watertightness induced by blocked surface pores of fully hydrated polymer-modified samples that create water film in addition to the water from PT that caused the increase.

3.2 Characterization of calcium hydroxide $(\mathrm{CH})$ and calcium silicate hydrate $(\mathrm{C}-\mathrm{S}-\mathrm{H})$ using XRD, TGA/DTG and SEM

XRD is used to observe the crystallinity of $\mathrm{CH}$ in the specimens where it can be evaluated at peaks 18.09, 34.09 and 47.12. Figure 6 assembles the XRD pattern of different ages for a particular specimen to evaluate the change in structural crystallinity. In Fig. 6, crystallinity of $\mathrm{CH}$ can be seen to slightly increase from day 28 to 60 but decrease thereafter. This shows interaction between $\mathrm{CH}$ and polymer took place where $\mathrm{CH}$ was crosslinked which can be seen manifesting the opposite pattern (at peaks (20) around $23.99^{\circ}$ and $29.75^{\circ}$ ).

Figure 6 shows the XRD spectra of mortar added with 10\% SAE, 10\% SBR and Control at 28, 60 and 90 days. It can be clearly seen that $\mathrm{CH}$ crystallinity decreased throughout the ages showing disturbance of $\mathrm{CH}$ structure caused by crosslink with ester anions as described in Section 3.1. Besides, change in C-S-H crystallinity pattern can be seen to be identical to the control sample implying that pozzolanic reaction occurred to the same extent as the polymer is not a type of pozzolan. The additional $\mathrm{C}-\mathrm{S}-\mathrm{H}$ produced did not react with $\mathrm{SAE}$ because of the competition with other ions such as $\mathrm{Si}^{4+}$ or $\mathrm{Si}^{4-}$, which maintained the increase in its crystallinity after 60 days. In addition, the effect of SBR in preventing efflorescence can also be observed using XRD patterns as in Fig. 6. Unlike the control and 10\%

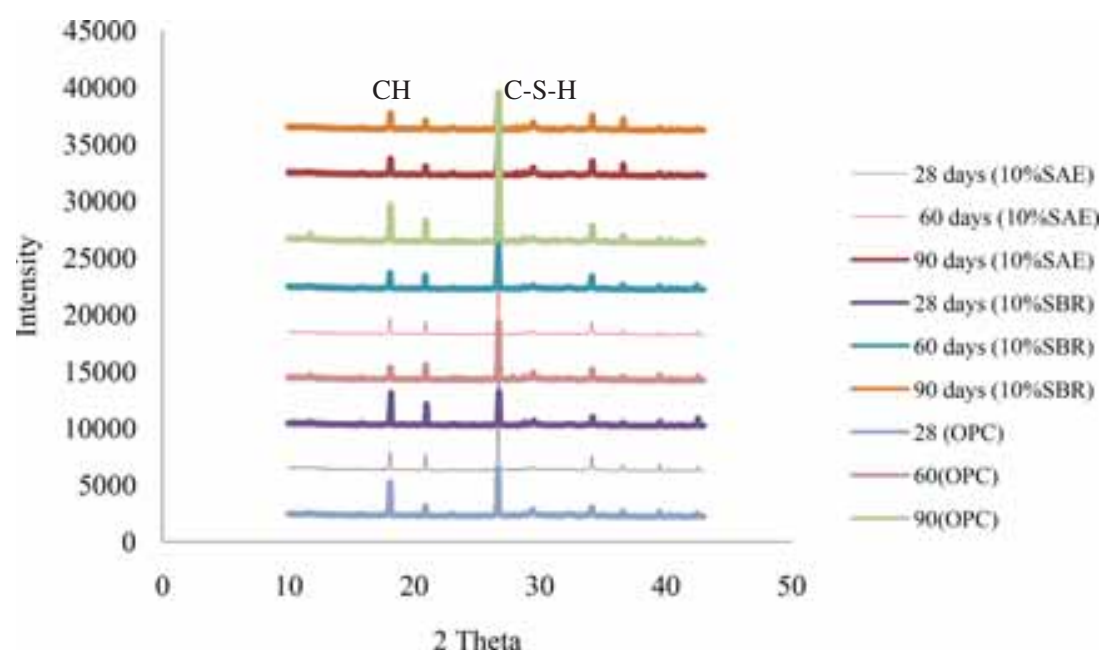

Figure 6: XRD pattern (CuK $\alpha$ radiation) of all samples at day 28, 60 and 90. 
SAE samples, crystalline $\mathrm{CH}$ structure in $10 \%$ SBR increased throughout the aging process, which means no sign of $\mathrm{CH}$ structure being disturbed. This also shows that $\mathrm{CH}$ did not leach from the system as it accumulated until after 90 days. For the product of pozzolanic activity, SBR also has no effect in its composition as SAE where the intensity increased all ages.

TGA/DTG patterns shown in Fig. 7 are used to confirm XRD results. The mass loss step at $425^{\circ} \mathrm{C}-550^{\circ} \mathrm{C}$ is primarily due to decomposition or dehydroxylation of $\mathrm{CH}$ into $\mathrm{H}_{2} \mathrm{O}$ and $\mathrm{CaO}$ [16]. Figure 7(a) shows $1.37 \%$ mass loss during this range, which indicates the approximate amount of $\mathrm{CH}$ in Control after 28 days while Fig. 7(b) and (c) show that $10 \% \mathrm{SAE}$ and $10 \%$ SBR contain $1.49 \%$ and $3.68 \% \mathrm{CH}$, respectively, at the same age. Therefore, it is evident that more $\mathrm{CH}$ is present in SBR samples compared to SAE and OPC.

Figure 8 shows the comparison of SEM images between Control, 10\% SBR and 10\% SAE at day 28. $\mathrm{CH}$ has a layered structure and tends to form hexagonal crystals. The morphology depends on the conditions of crystallinity, for example available space, temperature, impurities and the presence of admixtures such as polymers. The images confirm the XRD and TGA/DTG results by showing more $\mathrm{CH}$ manifesting in 10\% SBR than other samples. It can be clearly seen that there is no crystalline $\mathrm{CH}$ in SAE sample that shows the evidence of $\mathrm{CH}$ and polymer interaction [23]. Figures 9 and 10 corroborate these results as the least surface absorption of polymer-modified cement mortar in comparison to the unmodified ones.

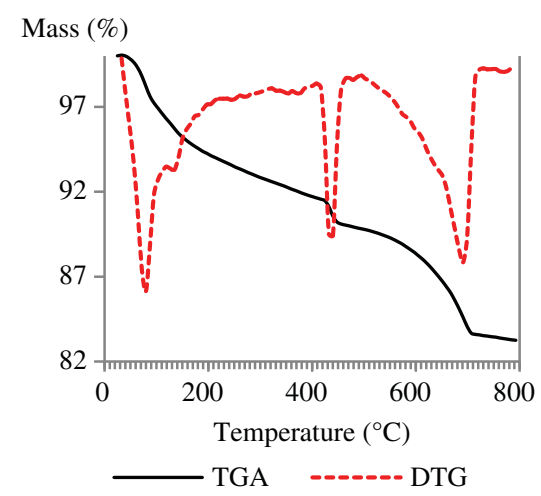

(a) Control (1.37\% mass loss of $\mathrm{CH})$

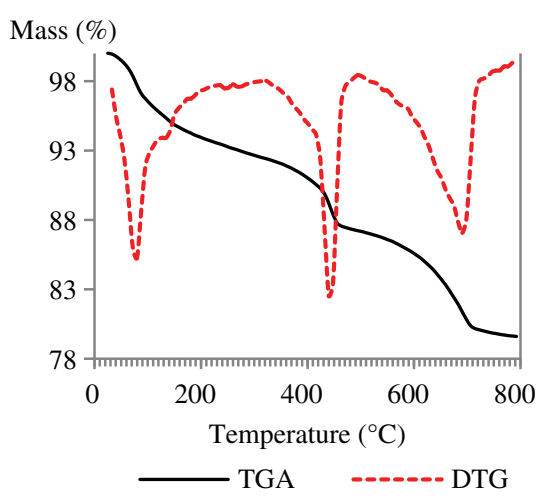

(b) $10 \% \mathrm{SBR}(3.68 \%$ mass loss of $\mathrm{CH})$

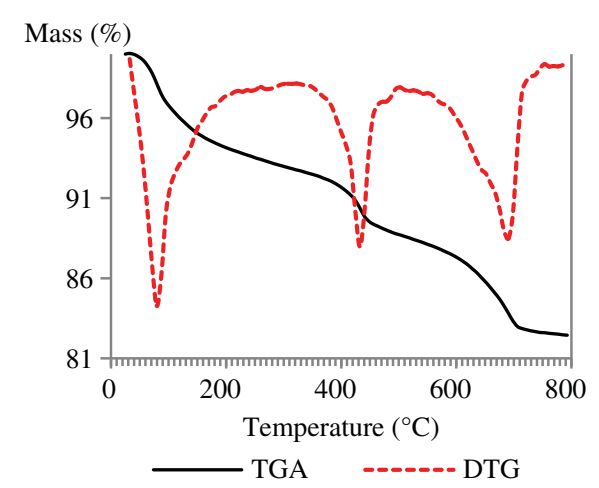

(c) $10 \%$ SAE $(1.49 \%$ mass loss of $\mathrm{CH})$

Figure 7: TGA/DTG of $10 \%$ SAE at day 28. 


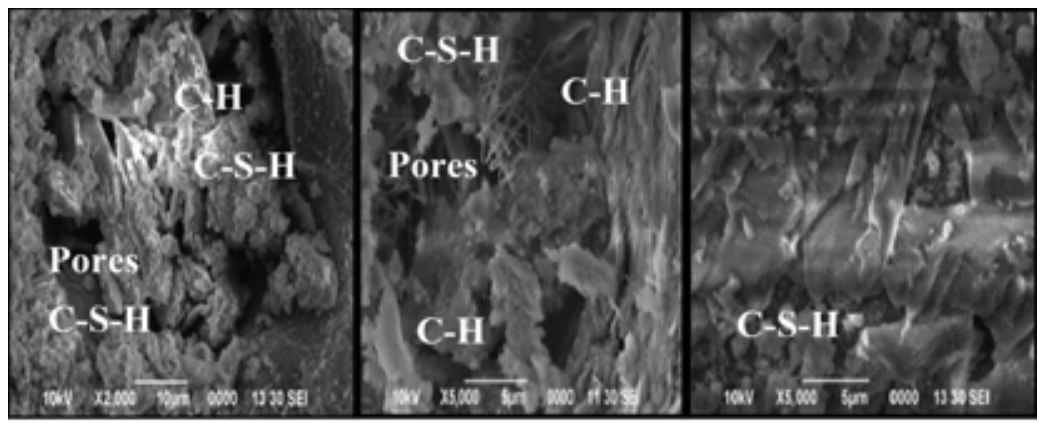

Control

SBR

SAE

Figure 8: SEM images of Control, 10\% SBR and 10\% SAE at day 28.

\section{Initial Surface Water Absorption Rate of Specimen d 28 w/c0.5}

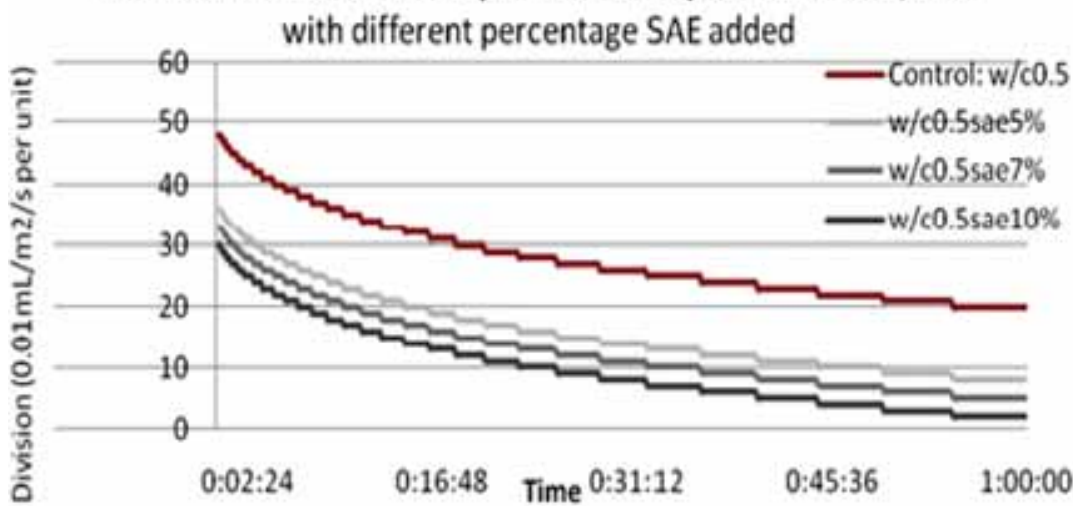

Figure 9: Comparison of 28 days ISAT between OPC mortar sample (Control) and SAEmodified samples.

Initial Surface Water Absorption Rate of Specimen d 28 w/c0.5 with different percentage SBR added

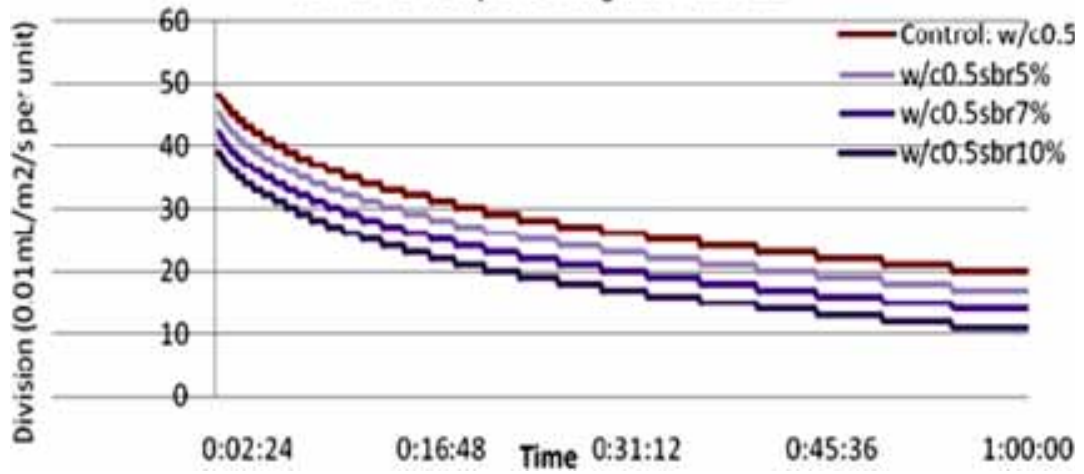

Figure 10: Comparison of 28 days ISAT between OPC mortar sample (Control) and SBRmodified samples. 


\section{CONCLUSIONS}

Results of this study show that SAE have positively influenced the efflorescence formation on mortar surfaces to a significant extent. It is caused by both crosslink reaction between SAE and $\mathrm{CH}$ and pore-blocking effects of SAE as hydration progressed in the microstructures of mortar. These behaviours were reflected in the XRD patterns, TGA/DTG analysis, SEM images and the least surface absorption of polymer-modified cement paste and mortar samples in comparison to the unmodified ones. It was further validated that the optimum level of SAE polymer addition to mortar was $10 \%$ and $5 \%$ by weight for primary and secondary efflorescence, respectively. Future investigations on the extent of reactivity of SAE and other reactive polymer, e.g. PAE (Polyacrylic Esters) with $\mathrm{CH}$ using other characterization methods are needed to understand efflorescence phenomenon and indirectly improve concrete durability and sustainability. For future analysis, study on the pores distribution of the samples by mercury intrusion porosimetry would be recommended in order to get accurate analysis on porosity.

\section{ACKNOWLEDGEMENTS}

The authors wish to acknowledge the Ministry of Education and University Malaysia Sarawak for supporting this work under the FRGS/03(04)/772/2010(53) grant.

\section{REFERENCES}

[1] Crouchore, P.N., Color: a force in construction. Concrete International, 7(11), pp. 43-45, 1985.

[2] Nasvik, J., Diagnosing problems with decorative concrete. Concrete Construction, 2003.

[3] Higgins, D.D., Efflorescence on concrete. Appearance Matters, No.4. Cement and Concrete Association: UK, 8 pp, 1982.

[4] Neville, A., Efflorescence-surface blemish of internal problem? Part 2: Situation in practice. Concrete International, 24(9), pp. 85-88, 2002.

[5] Neville, A., Efflorescence-surface blemish of internal problem? Part 1: The knowledge. Concrete International, 24(8), pp. 86-90, 2002.

[6] Bensted, J., Efflorescence-prevention is better than cure. Concrete, 34, pp. 40-41, 2000.

[7] Kresse, P., Coloured concrete and its enemy: efflorescence. Chemistry and Industry, pp. 93-95, 1989.

[8] Horgnies, M., Willieme, P. \& Gabet, O., Influence of the surface properties of concrete on the adhesion of coating: characterization of the interface by peel test and FT-IR spectroscopy. Progress in Organic Coatings, 72(3), pp. 360-379, 2011. doi: http://dx.doi. org/10.1016/j.porgcoat.2011.05.009

[9] Deichnel, T., Efflorescence-origins, causes, counter-measures. Betonwerk+FertigteilTechnik, 48, pp. 590-597, 1982.

[10] Kresse, P., Efflorescence-mechanism of occurrence and possibilities of prevention. Betonwerk +Fertigteil-Technik, 53, pp. 160-168, 1987.

[11] Kresse, P., Efflorescence and its prevention. Betonwerk+Fertigteil-Technik, 57, pp. 84-88, 1991.

[12] Kresse, P., Studies of the phenomenon of efflorescence on concrete and asbestos cement. Betonwerk+Fertigteil-Technik, 49, pp. 560-568, 1983.

[13] Bensted, J., Efflorescence-a visual problem on buildings. Construction Repair, 8, pp. 47-49, 1994. 
[14] Dhir, R.K., McCarthy, M.J. \& Newlands, M.D., Challenges in designing concrete durability: a sustainable approach. University of Dundee, UK: Concrete Technology Unit, 2009.

[15] Older, I., Hydration, setting and hardening of Portland cement. Lea's Chemistry of Cement and Concrete, 4th edn., Arnold: London, 1998.

[16] Taylor, H.F.W., Cement Chemistry, 2nd edn., Thomas Telford: London, 1997. doi: http://dx.doi.org/10.1680/cc.25929

[17] Dow, C. \& Glassier F.P., Calcium carbonate efflorescence on Portland cement and building materials. Cement and Concrete Research, 33, pp. 147-154, 2003. doi: http:// dx.doi.org/10.1016/S0008-8846(02)00937-7

[18] Mohamed, S.N., Hamdan, S. \& Yakub, I., Calcium carbonate efflorescence on pozzolanic modified mortar. International Journal of Advancements Civil Structural and Environmental Engineering-IJACE, 1(1), pp. 56-59, 2013.

[19] Lanzon, M., Garrido, A. \& Garcia-Ruiz, P.A., Stabilization of sodium oleate as calcium oleate in cement-based mortars made with limestone fillers. Construction and Building Materials, 25(2), pp. 1001-1008, 2011. doi: http://dx.doi.org/10.1016/j.conbuildmat.2010.06.079

[20] Izaguirre, A., Lanas, J. \& Alvarez, J.I., Effect of water-repellent admixtures on the behaviour of aerial lime-based mortars. Cement and Concrete Research, 39(11), pp. 1095-1104, 2009. doi: http://dx.doi.org/10.1016/j.cemconres.2009.07.026

[21] Ohama, Y., Recent progress in concrete-polymer composites. Advance Cement Based Materials, 5(2), pp. 31-40, 1997. doi: http://dx.doi.org/10.1016/S10657355(96)00005-3

[22] Ohama, Y., Polymer-based admixtures. Cement and Concrete Composites, 20(2-3), pp.189-212, 1998. doi: http://dx.doi.org/10.1016/S0958-9465(97)00065-6

[23] Ohama, Y. \& Chandra, S., Polymers in Concrete, CRC Press: Florida, 1994.

[24] Aziz, M.A., Engineering Materials. Kazi Mahfuzur Rahman: Dhaka, 1995.

[25] Gomes, C.E.M. \& Ferreira, O.P., Analysis of microstructural properties of VA/VEAVA coplymer modified cement pastes. Polimeros: Ciencia e Tecnologia, 15(3), pp. 193-198, 2005. doi: http://dx.doi.org/10.1590/S0104-14282005000300009 